\title{
Glucocorticoids regulate AKR1D1 activity in human liver in vitro and in vivo
}

\author{
Nikolaos Nikolaou1 ${ }^{1}$ Anastasia Arvaniti1,2,*, Nathan Appanna1,*, Anna Sharp1, Beverly A Hughes³, Dena Digweed4, \\ Martin J Whitaker ${ }^{4}$, Richard Ross ${ }^{5}$, Wiebke Arlt3,6, Trevor M Penning7, Karen Morris ${ }^{8}$, Sherly George ${ }^{8}$, Brian G Keevil8 \\ Leanne Hodson', Laura L Gathercole1,2 and Jeremy W Tomlinson'1
}

1Oxford Centre for Diabetes, Endocrinology and Metabolism, NIHR Oxford Biomedical Research Centre, University of Oxford, Churchill Hospital, Oxford, UK

2Department of Biological and Medical Sciences, Oxford Brookes University, Oxford, UK

3Institute of Metabolism and Systems Research, University of Birmingham, Edgbaston, Birmingham, UK

${ }^{4}$ Diurnal Ltd, Cardiff, UK

5Department of Oncology and Metabolism, Faculty of Medicine, Dentistry and Health, University of Sheffield, Sheffield, UK

${ }^{6}$ NIHR Birmingham Biomedical Research Centre, University Hospitals Birmingham NHS Foundation Trust and University of Birmingham, Birmingham, UK 7Department of Systems Pharmacology \& Translational Therapeutics, University of Pennsylvania Perelman School of Medicine, Philadelphia, Pennsylvania, USA

8Biochemistry Department, Manchester University NHS Trust, Manchester, UK

Correspondence should be addressed to J W Tomlinson: jeremy.tomlinson@ocdem.ox.ac.uk

*(A Arvaniti and N Appanna contributed equally to this work)

\begin{abstract}
Steroid $5 \beta$-reductase (AKR1D1) is highly expressed in human liver where it inactivates endogenous glucocorticoids and catalyses an important step in bile acid synthesis. Endogenous and synthetic glucocorticoids are potent regulators of metabolic phenotype and play a crucial role in hepatic glucose metabolism. However, the potential of synthetic glucocorticoids to be metabolised by AKR1D1 as well as to regulate its expression and activity has not been investigated. The impact of glucocorticoids on AKR1D1 activity was assessed in human liver HepG2 and Huh7 cells; AKR1D1 expression was assessed by qPCR and Western blotting. Genetic manipulation of AKR1D1 expression was conducted in HepG2 and Huh7 cells and metabolic assessments were made using qPCR. Urinary steroid metabolite profiling in healthy volunteers was performed pre- and postdexamethasone treatment, using gas chromatography-mass spectrometry. AKR1D1 metabolised endogenous cortisol, but cleared prednisolone and dexamethasone less efficiently. In vitro and in vivo, dexamethasone decreased AKR1D1 expression and activity, further limiting glucocorticoid clearance and augmenting action. Dexamethasone enhanced gluconeogenic and glycogen synthesis gene expression in liver cell models and these changes were mirrored by genetic knockdown of AKR1D1 expression. The effects of AKR1D1 knockdown were mediated through multiple nuclear hormone receptors, including the glucocorticoid, pregnane $\mathrm{X}$ and farnesoid $\mathrm{X}$ receptors. Glucocorticoids down-regulate AKR1D1 expression and activity and thereby reduce glucocorticoid clearance. In addition, AKR1D1 down-regulation alters the activation of multiple nuclear hormone receptors to drive changes in gluconeogenic and glycogen synthesis gene expression profiles, which may exacerbate the adverse impact of exogenous glucocorticoids.
\end{abstract}

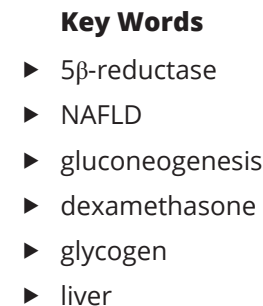

Journal of Endocrinology (2020) 245, 207-218 (c) 2020 The authors Published by Bioscientifica Ltd. Printed in Great Britain

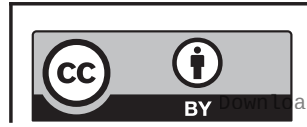

This work is licensed under a Creative Commons Attribution 4.0 International License. ded from Bioscientifica.com at 04/26/2023 02:10:43PM 


\section{Introduction}

Glucocorticoids (GCs) are steroid hormones that are released in response to stress and play a crucial role in inflammation and in carbohydrate, lipid and protein metabolism. Within key metabolic target tissues, notably the liver, the availability of GCs to bind and activate the GC receptor (GR) is controlled by a series of prereceptor enzymes that inactivate or regenerate active GCs. In this regard, the role of the $11 \beta$-hydroxysteroid dehydrogenases (11ß-HSD, type 1 and 2 ) and the $5 \alpha$-reductases (type 1 and 2 ) are well established (Morgan et al. 2014, Nasiri et al. 2015). We have recently shown that $5 \beta$-reductase (AKR1D1) is also a potent regulator of GC availability and GR activation in human hepatocytes (Nikolaou et al. 2019a).

AKR1D1 is a member of the aldo-keto-reductase (AKR) superfamily 1 of enzymes and is the first member of the 1D subfamily (Onishi et al. 1991, Faucher et al. 2008). The human gene consists of nine exons and six transcript variants that have been identified, three of which lead to functional protein isoforms. AKR1D1 is principally expressed in the liver, where levels are more than ten-fold higher than in any other tissue (Chen \& Penning 2014). In addition to governing GC availability (as well as the availability of other steroid hormones including progesterone and androgens) (Kondo et al. 1994, Chen et al. 2011, Nikolaou et al. 2019a), we have shown that AKR1D1 has an important role in regulating lipid metabolism in human hepatocytes, largely, although not exclusively, through its role to limit the generation of bile acids (BAs) that can activate the farnesoid $\mathrm{X}$ receptor (FXR) (Nikolaou et al. 2019b).

However, important questions remain unanswered regarding the role of AKR1D1 in GC metabolism, specificially with regard to regulation of AKR1D1 expression and activity by GCs, the capacity of AKR1D1 to metabolise synthetic steroids and its role in the regulation of established GC target genes. There is a precedent for GCs regulating their own pre-receptor metabolism. GCs are known to increase $11 \beta$-HSD1 activity and expression and this has been postulated as a mechanism driving local GC excess and fueling an adverse metabolic phenotype (Jamieson et al. 1995, Dube et al. 2015). While the differential feedback of BAs to regulate AKR1D1 expression has been previously described (Valanejad et al. 2017), to date, the interplay between GCs and AKR1D1 expression and activity has not been explored.

Our study therefore had two major aims; first, to examine the potential for GCs to regulate AKR1D1 expression and activity and, secondly, to determine if established GC sensitive molecular targets are also regulated by changes in AKR1D1 and, if so, whether this is mediated through GR or non-GR mediated mechanisms.

\section{Materials and methods}

\section{Cell culture}

HepG2 cells (Cat\#HB-8065) and HEK293 cells (Cat\#CRL-11268) were purchased from ATCC. Huh7 cells were purchased from the Japanese Cancer Research Resources Bank (Cat\#JCRB0403). All cell lines were cultured in Dulbecco's minimum essential medium (DMEM) (Thermo Fisher Scientific), containing $4.5 \mathrm{~g} / \mathrm{L}$ glucose and supplemented with $10 \%$ fetal bovine serum, $1 \%$ penicillin/streptomycin and $1 \%$ non-essential amino acids (Thermo Fisher Scientific).

Dexamethasone (500 nM), cortisol (500 nM), prednisolone (500 nM), GW4064 $(5 \mu \mathrm{M})$, GSK2033 (100 nM), 22(S)-hydroxycholesterol $(10 \mu \mathrm{M})$ and RU486 $(5 \mu \mathrm{M})$ were purchased from Sigma-Aldrich. SPA70 $(10 \mu \mathrm{M})$ was purchased from Axon Medchem (Groningen, Netherlands). For all cell treatments, HEK293, HepG2 and Huh7 cells were cultured in serum-free and phenol redfree media containing $4.5 \mathrm{~g} / \mathrm{L}$ glucose and supplemented with $10 \%$ fetal bovine serum, $1 \%$ penicillin/streptomycin and $1 \%$ non-essential amino acids.

\section{Transfection studies}

AKR1D1 over-expression studies were performed in 12-well cell bind plates (Corning). The pCMV6-XL4+AKR1D1 (Origene Technologies, Rockville, MD, USA) construct was used and $0.5 \mu \mathrm{g}$ DNA and $1 \mu \mathrm{L}$ X-tremeGENE DNA transfection reagent (Roche) were diluted in $100 \mu \mathrm{L}$ OPTIMEM serum-free media (Invitrogen). The mixture was vortexed and incubated at room temperature for $20 \mathrm{~min}$ and, subsequently, $100 \mu \mathrm{L}$ was added to each well and cells were incubated at $37^{\circ} \mathrm{C}$ for $48 \mathrm{~h}$ prior to treatment.

For AKR1D1 knockdown studies, cells were plated in 24-well cell bind plates (Corning). AKR1D1 siRNA molecules (HSS1101183, HSS1101184) were purchased from Invitrogen. $20 \mathrm{nmol}$ of AKR1D1 siRNA was diluted in $25 \mu \mathrm{L}$ OPTIMEM serum-free media (Invitrogen) and, in a separate tube, $2.5 \mu \mathrm{L}$ Lipofectamine RNAiMAX (Invitrogen) was diluted in $25 \mu \mathrm{L}$ OPTIMEM serum-free media. The contents of the two tubes were combined by gentle pipetting and incubated at room temperature for $5 \mathrm{~min}$. 
$50 \mu \mathrm{L}$ of the resulting transfection solution was added drop-wise and cells were incubated at $37^{\circ} \mathrm{C}$ for $48 \mathrm{~h}$ prior to treatment.

\section{Luciferase reporter assay}

To determine GR activation, HEK293 cells were plated in 24-well cell bind plates (Corning) and co-transfected with AKR1D1 over-expression vector (as described above) and GRE-reporter: a mixture of an inducible GRE-responsive firefly luciferase construct and a constitutively expressing renilla luciferase construct (\#CCS-006L, Qiagen). Cell lysates were harvested in passive lysis buffer, and reporter activity was measured using the Luciferase Assay System (Promega) and an EnSpire Multimode plate reader (PerkinElmer). The data were presented as the percentage ratio of firefly to renilla luciferase activity (Fluc/Rluc).

\section{RNA extraction and gene expression (quantitative PCR)}

Total RNA was extracted from cells using the Tri-Reagent system (Sigma-Aldrich), and RNA concentrations were determined spectrophotometrically at OD260 on a Nanodrop spectrophotometer (ThermoFisher Scientific). RT was performed in a $20 \mu \mathrm{L}$ volume; $1 \mu \mathrm{g}$ of total RNA was incubated with 10x RT Buffer, $100 \mathrm{mM}$ dNTP Mix, 10× RT Random Primers, $50 \mathrm{U} / \mu \mathrm{L}$ MultiScribe Reverse Transcriptase and $20 \mathrm{U} / \mu \mathrm{L}$ RNase Inhibitor (ThermoFisher Scientific). The reaction was performed under the following conditions; $25^{\circ} \mathrm{C}$ for $10 \mathrm{~min}, 37^{\circ} \mathrm{C}$ for $120 \mathrm{~min}$ and then terminated by heating to $85^{\circ} \mathrm{C}$ for $5 \mathrm{~min}$.

All quantitative PCR (qPCR) experiments were conducted using an ABI 7900HT sequence detection system (Perkin-Elmer Applied Biosystems). Reactions were performed in $6 \mu \mathrm{L}$ volumes on 384-well plates in reaction buffer containing $3 \mu \mathrm{L}$ of $2 \times$ Kapa Probe Fast qPCR Master Mix (Sigma-Aldrich). All probes were supplied by Thermo Fisher Scientific as predesigned TaqMan Gene Expression Assays (FAM dye-labeled). The reaction conditions were $95^{\circ} \mathrm{C}$ for $3 \mathrm{~min}$, then 40 cycles of $95^{\circ} \mathrm{C}$ for $3 \mathrm{~s}$ and $60^{\circ} \mathrm{C}$ for $20 \mathrm{~s}$. The $\mathrm{Ct}(\mathrm{dCt})$ of each sample using the following calculation (where $\mathrm{E}$ is reaction efficiency, determined from a standard curve): $\Delta \mathrm{Ct}=\mathrm{E}^{(\min \mathrm{Ct}-\text { sample } \mathrm{Ct})}$ using the $1 / 40$ dilution from a standard curve generated from a pool of all cDNAs as the calibrator for all samples. The relative expression ratio was calculated using the following formula: Ratio $=\Delta \mathrm{Ct}_{\text {(target) }} / \Delta \mathrm{Ct} \mathrm{t}_{\text {(ref) }}$ and expression values were normalized to 18SrRNA (Pfaffl 2001).

\section{Protein extraction and immunoblotting}

Total protein was extracted from cells using RIPA buffer $\left(150 \mathrm{mM} \mathrm{NaCl}, 1.0 \%\right.$ IGEPAL ${ }^{\circledR}$ CA-630, 0.5\% sodium deoxycholate, $0.1 \%$ SDS, and $50 \mathrm{mM}$ Tris, $\mathrm{pH}$ 8.0) (SigmaAldrich) and protease inhibitor cocktail (Thermo Fisher Scientific). Protein concentrations were measured using a commercially available assay (Bio-Rad Laboratories) according to the manufacturer's protocol. Primary human AKR1D1 (dilution 1/250; HPA057002, Atlas Antibodies AB, Bromma, Sweden), GILZ (sc-133215, Santa Cruz Biotechnology), $\beta$-tubulin (\#15115, monoclonal) (Cell Signaling), $\beta$-actin (\#3700, monoclonal) (Cell Signaling), CYP8B1 (\#PA5-37088, polyclonal) (ThermoFisher Scientific) and secondary antibodies (P044801-2, polyclonal) from Dako (Agilent) were used at a dilution of $1 / 1000$ (primary) and $1 / 2000$ (secondary) respectively, unless stated otherwise. Bands were visualised with Bio Rad Clarity Western ECL and ChemiDocXS imager (Bio Rad). Western blots were quantified by densitometry analysis using ImageJ (https://imagej.nih.gov/ij/), normalised to $\beta$-tubulin to correct for variability in gel loading.

\section{Clinical protocol}

The study was approved by the South East Wales Research Ethics Committee, and all participants gave written informed consent. The study protocol was authorised by the Medicines and Healthcare products Regulatory Agency (EudraCT number: 2013-000259-42). Fourteen healthy male participants with no significant past medical history and who were on no regular prescribed medication were recruited into the study and investigated on two occasions. On their first assessment, participants performed a timed $(8 \mathrm{~h})$ urine collection starting at 24:00 $\mathrm{h}$ and ending at 08:00 $\mathrm{h}$ the following morning. On their second assessment, they took dexamethasone $1 \mathrm{mg}$ at 23:00 $\mathrm{h}$, and then performed the timed urine collection from 24:00 to $08: 00 \mathrm{~h}$ as before. Urine collection aliquots were stored at $-20^{\circ} \mathrm{C}$ until analysis by gas chromatographymass spectrometry as described.

\section{Steroid hormone measurements}

For in vitro media steroid hormone treatments, quantitative gas chromatography-mass spectrometry (GC-MS) was undertaken in selected ion-monitoring analysis mode as described previously (Shackleton 1986). An Agilent 5973 instrument was used in a selected ion monitoring mode and the following steroids were identified: cortisol, cortisone,

This work is licensed under a Creative Commons Attribution 4.0 International License. 
$5 \beta$-tetrahydrocortisone (5 $\beta$-THE), $5 \beta$-tetrahydrocortisol

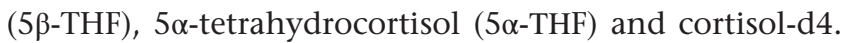
Cortisol was positively identified by comparison to an authentic reference standard that gave a double peak at approximately $24.17 \mathrm{~min}$, monitored ion was 605 . Cortisone was positively identified by comparison to an authentic reference standard that gave a double peak at approximately $23.20 \mathrm{~min}$, monitored ion was ion 531 . The monitored ions for $5 \beta$-THE and $5 \beta$-THF were 578 and 562, respectively, and were positively identified at approximately $18.87 \mathrm{~min}$ and $19.95 \mathrm{~min}$, respectively. In selected experiments, cell media cortisone levels were also determined using a commercially available cortisone ELISA assay ( $<0.1 \%$ cross-reactivity with dexamethasone), according to the manufacturer's protocol (Invitrogen). Cell media prednisolone and dexamethasone were measured by liquid chromatography-mass spectrometry (LC-MS/MS) using previously published methods (Owen et al. 2005, Hawley et al. 2018). The lower limit of quantitation was $5.2 \mathrm{nmol} / \mathrm{L}$ and $0.25 \mathrm{nmol} / \mathrm{L}$ for prednisolone and dexamethasone, respectively.

Urinary corticosteroid metabolite analysis was performed by GC-MS, as described previously (Shackleton 1986, Palermo et al. 1996). Total cortisol metabolites were defined as the sum of cortisol, 6-OH-cortisol, cortisone, $5 \beta$-THF, $5 \alpha$-THF, $5 \beta$-THE, $\alpha$-cortolone, $\beta$-cortolone, $\alpha$-cortol and $\beta$-cortol. $5 \beta$-THF is the $5 \beta$-reduced metabolite generated by AKR1D1, whilst $5 \alpha$-THF is generated through the activity of $5 \alpha$-reductases (type 1 and 2). The $5 \beta$-THF $/ 5 \alpha$-THF ratio provides a measure of the relative activity of AKR1D1 and $5 \alpha$-reductases.

\section{Statistics}

Data are presented as mean \pm s.E., unless otherwise stated. Normal distribution was confirmed using Shapiro-Wilk test. Two-tailed, paired $t$-tests were used to compare single treatments to control. For comparisons between control and different treatments, statistical analysis was performed using one-way ANOVA with Dunnett corrections. To compare mean differences between groups that had been split on multiple treatments, doses or times, twoway ANOVA with Sidak corrections was used. Statistical analysis on qPCR data was performed on mean relative expression ratio values (Ratio $=\Delta \mathrm{Ct}(\operatorname{target}) / \Delta \mathrm{Ct}$ (Pfaffl 2001)). Data analysis was performed using Graphpad Prism software (Graphpad Software Inc) and considered statistically significant at $P<0.05$, unless otherwise stated.

\section{Results}

\section{AKR1D1 differentially regulates endogenous and synthetic glucocorticoid clearance in vitro}

We first explored the capacity of AKR1D1 to metabolise endogenous and synthetic GCs. HEK293 cells were transfected with either empty pCMV6-XL4 vector (EV) or AKR1D1 containing vector (Origene Technologies) for $48 \mathrm{~h}$. Successful over-expression was confirmed using qPCR and Western blotting (Supplementary Fig. 1A and B, see section on supplementary materials given at the end of this article).

Following AKR1D1 over-expression, HEK293 cells were treated with cortisol, prednisolone or dexamethasone $(500 \mathrm{nM}, 24 \mathrm{~h})$ and cell media GC concentrations measured using mass-spectrometry. Cortisol was almost completely cleared within $24 \mathrm{~h}$ in cells over-expressing AKR1D1 in comparison with empty vector controls (Fig. 1A). In contrast, there was only partial clearance of prednisolone (33\%) and dexamethasone (15\%) (Fig. 1B and $\mathrm{C}$ ). To determine the impact of these observations on GR activation, dual transfection experiments were performed. HEK293 cells were transfected with both the AKR1D1 expressing vector and a commercially available GR-element (GRE) luciferase construct. Consistent with the mass-spectrometry data, AKR1D1 over-expression decreased cortisol-mediated GR activation (EV: 100\% vs AKR1D1: $43.1 \pm 1.2 \%, P<0.001)$. The impact on prednisolone-mediated GR activation was less marked, but remained significant (EV: $100 \%$ vs AKR1D1: $73.0 \pm 4.4 \%$, $P<0.05)$. There was no effect of AKR1D1 over-expression on dexamethasone-mediated GR activation (EV: 100\% vs AKR1D1: $94.0 \pm 10.8 \%, P=$ ns) (Fig. 1D).

\section{Cortisol fails to regulate GC target genes in human hepatoma cells due to rapid clearance}

To further demonstrate the potent ability of human hepatoma cell lines to clear endogenous cortisol, HepG2 human hepatoma cells were treated with cortisol $(500 \mathrm{nM}$, $24 \mathrm{~h}$ ). Cortisol failed to regulate hepatic gene expression (Fig. 2A, B and C). Subsequent GC-MS analysis of the cell media demonstrated enhanced clearance of cortisol with a parallel increase in cortisone production, as a result of endogenous $5 \alpha \mathrm{R} / 5 \beta \mathrm{R}$ and $11 \beta$-HSD 2 activity, respectively (Fig. 2D). As expected, the levels of $5 \beta$-reduced metabolites of cortisol and cortisone, $5 \beta$-THF and $5 \beta$-THE, increased significantly (Fig. 2E). These data suggest that increased https://joe.bioscientifica.com https://doi.org/10.1530/JOE-19-0473 (c) 2020 The authors Published by Bioscientifica Ltd. Printed in Great Britain

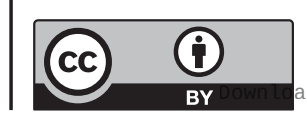

This work is licensed under a Creative Commons Attribution 4.0 International License. ed from Bioscientifica.com at 04/26/2023 02:10:43PM 

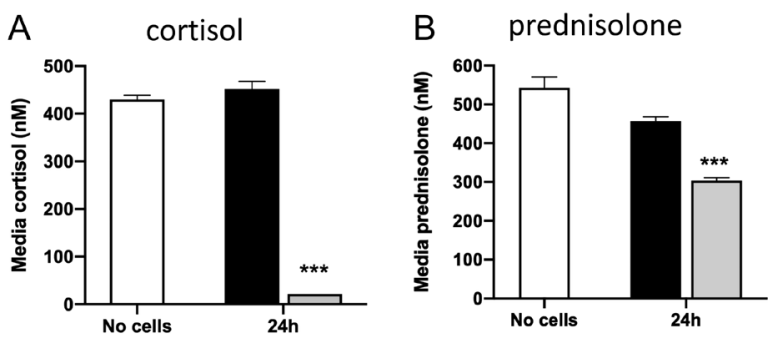

C dexamethasone
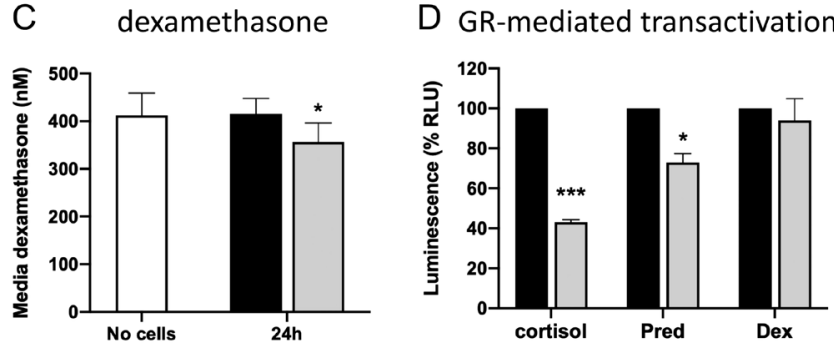

\section{Figure 1}

AKR1D1 differentially regulates endogenous and synthetic GC metabolism in vitro. AKR1D1 over-expression (grey bars) increases cortisol (A) and prednisolone clearance (B), following $24 \mathrm{~h}$ of treatment, compared to no-cell controls (white bars) or vector only transfected cells (black bars). AKR1D1 over-expression had a limited, although significant effect on dexamethasone clearance, following $24 \mathrm{~h}$ of treatment, compared to no-cell controls (white bars) or vector only transfected cells (black bars) (C). AKR1D1 over-expression (grey bars) significantly decreased activation of the glucocorticoid receptor in HEK293 cells, following cortisol and prednisolone treatment, but not following dexamethasone treatment (all $500 \mathrm{nM}, 24 \mathrm{~h}$ ), as measured by activation of GRE-luciferase-reporter (D) Firefly luciferase activity was normalised to renilla luciferase. Data are presented as mean \pm S.E. of $n=8$ experiments, performed in duplicate. $\star P<0.05, * \star \star P<0.001$, compared to vector only transfected controls.

cortisol clearance underpins the lack of effect of cortisol on gene expression in HepG2 cells.

\section{Dexamethasone treatment down-regulates AKR1D1 expression and activity in vitro and in vivo}

Due to its limited clearance by AKR1D1, dexamethasone was used to examine the potential regulation of AKR1D1 activity and expression by GCs. HepG2 cells were treated with dexamethasone (500 nM) for $24 \mathrm{~h}$; successful activation of the GR was confirmed by elevated mRNA levels of the GR-regulated genes DUSP1 and GILZ, with a concomitant increase in GILZ protein expression (Fig. 3A and B). Dexamethasone decreased AKR1D1 mRNA and protein expression, without impacting on the expression of SRD5A1 and 11BHSD2 (Fig. 3C and D). To assess functional AKR1D1 activity, cortisone (which is metabolised by AKR1D1 in hepatocytes) clearance ( $200 \mathrm{nM}, 8 \mathrm{~h}$ ) was measured in cells that had been treated with dexamethasone. Paralleling the gene expression data, dexamethasone limited cortisone clearance in HepG2 cells, consistent with decreased AKR1D1 expression (Fig. 2E). In addition to regulating AKR1D1, dexamethasone increased the expression of other key genes involved in the BA synthetic pathway, including CYP7A1, CYP8B1 and $H S D 3 B 7$ (Fig. 3F).

GILZ mRNA expression was increased following treatment with dexamethasone $(500 \mathrm{nM}, 24 \mathrm{~h})$ and, as expected, this was abolished following co-treatment with RU486 (5 $\mu \mathrm{M}, 24$ h) (Supplementary Fig. 2A). In a similar manner, the down-regulation of AKR1D1 by dexamethasone (both mRNA and protein) was reversed by co-treatment with RU486 (Fig. 4A and B), indicative of a GR-dependent mechanism. RU486 treatment also prevented the dexamethasone-induced increased expression of CYP7A1 and CYP8B1 (Fig. 4C, D and Supplementary Fig. 2B).

Additional experiments were performed in Huh7 human hepatoma cells. Similar patterns of gene expression changes were observed with decreased AKR1D1 and increased CYP7A1, CYP8B1 and HSD3B7 mRNA levels following dexamethasone treatment $(500 \mathrm{nM}, 24 \mathrm{~h})$. The data are summarised in Table 1.
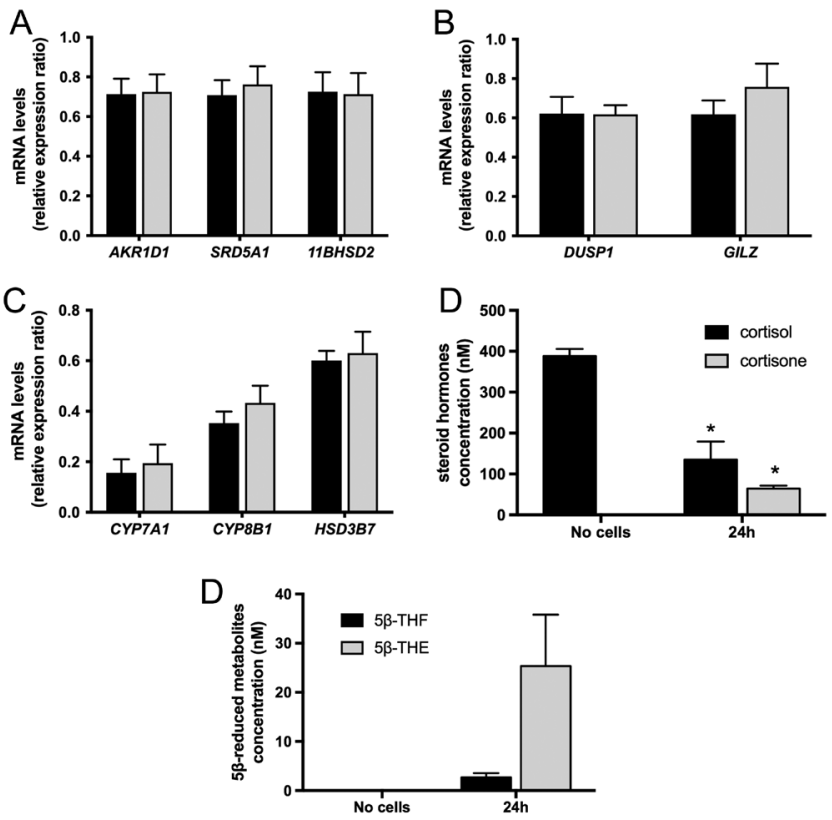

Figure 2

Endogenous GCs fail to regulate AKR1D1 expression in vitro. Cortisol treatment of HepG2 cells $(500 \mathrm{nM}, 24 \mathrm{~h}$ ) has no effect on the expression of steroid metabolising, glucocorticoid receptor regulated or bile acid synthesis genes ( $A, B$ and $C$ ). Mass spectrometry analysis of cell culture media demostrates increased cortisol clearance with a parallel increase in cortisone formation, indicative of $11 \beta-$ HSD2 activity (D). Cell culture media $5 \beta$-tetrahydrocortisol ( $5 \beta$-THF) and $5 \beta$-tetrahydrocortisone ( $5 \beta$-THE) levels increased following cortisol treatment ( $500 \mathrm{nM}, 24 \mathrm{~h}$ ) (E). qPCR data were normalised to 18SrRNA. Data are presented as mean \pm S.E. of $n=5$ experiments, performed in triplicate, $* P<0.05$, compared no-cell controls. 
A

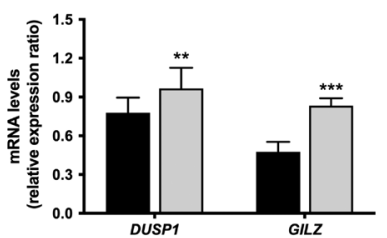

C
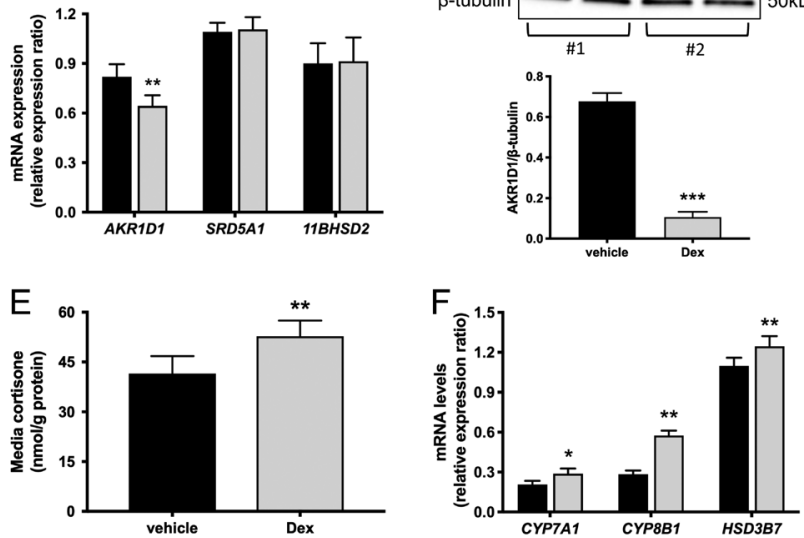

Figure 3

Synthetic GCs down-regulate AKR1D1 expression and activity in vitro. Dexamethasone treatment of HepG2 cells (500 nM, 24 h) increases the mRNA and protein expression of the glucocorticoid regulated genes, DUSP1 and GILZ (A and B). Dexamethasone treatment decreases the mRNA and protein expression of AKR1D1, but it had no effect on the expression of the steroid-metabolising genes SRD5A1 and 11BHSD2 (C and D), with a concomitant decrease in cortisone clearance, following $8 \mathrm{~h}$ of cortisone treatment (200 nM) (E). Dexamethasone treatment increases the expression of the bile acid synthesis genes CYP7A1, CYP8B1 and HSD3B7 (F). Representative Western blot images are shown, and formal quantification was performed in $n=5$ replicates. QPCR data were normalised to 18SrRNA. Data are presented as mean \pm S.E. of $n=5-7$ experiments, performed in triplicate, $* P<0.05$, $* * P<0.01$, $* \star \star P<0.001$, compared vehicle-treated controls.

To determine if our in vitro observations had relevance in vivo, we examined urinary steroid profiles in an overnight timed $(8 \mathrm{~h})$ urine collection from 14 healthy male participants (age: $32.9 \pm 3.1$ years, BMI: $24.7 \pm$ $0.5 \mathrm{~kg} / \mathrm{m}^{2}$ ) investigated on two occasions, one with and one without dexamethasone treatment $(1 \mathrm{mg})$, administered at the start of the timed urine collection.

As expected, total cortisol metabolites decreased following dexamethasone treatment consistent with suppression of the hypothalamo-pituitary-adrenal axis $(1898 \pm 162$ vs $1308 \pm 135 \mu \mathrm{g} / 8 \mathrm{~h}, P<0.01)$. While there was no change in $5 \alpha$-THF levels, the production of the $5 \beta$-reduced metabolite of cortisol, 5 5 -THF, decreased following dexamethasone treatment (Fig. 5A and B).
The $5 \beta$-THF $/ 5 \alpha$-THF ratio also decreased (Fig. 5C), data consistent with a dexamethasone-mediated selective reduction in AKR1D1 activity with no impact on $5 \alpha$-reductase activity.

\section{AKR1D1 knockdown alters glucose metabolism gene expression through FXR, GR, and PXR-dependent mechanisms}

GCs have a profound effect on carbohydrate metabolism through upregulation of hepatic gluconeogenesis and glycogen synthesis (Sistare \& Haynes 1985, Schneiter \& Tappy 1997, Tounian et al. 1997). Dexamethasone treatment of HepG2 cells (500 nM, $24 \mathrm{~h}$ ) increased mRNA expression related to these two processes, namely phosphoenolpyruvate carboxykinase (PEPCK), pyruvate carboxylase $(P C)$, fructose-bisphosphatase 1 (FBP1) and glycogen synthase (GYS1) mRNA expression (Supplementary Fig. 2C).

Successful AKR1D1 knockdown in HepG2 cells was achieved using siRNA techniques (AKR1D1 siRNA variant
A

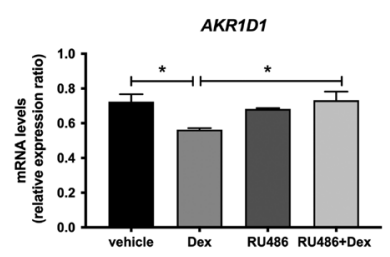

C

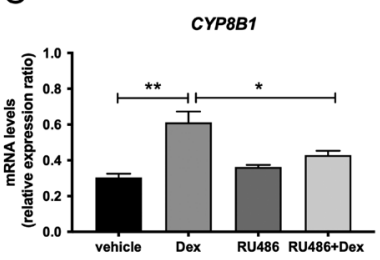

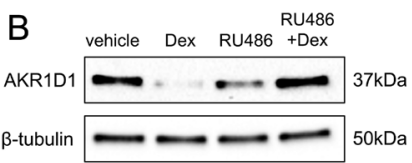

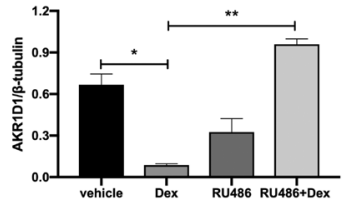

D vehicle Dex RU486 $\begin{array}{r}\mathrm{RU} 486 \\ +\mathrm{Dex}\end{array}$

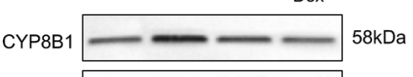

$\beta$-actin $=45 \mathrm{kDa}$

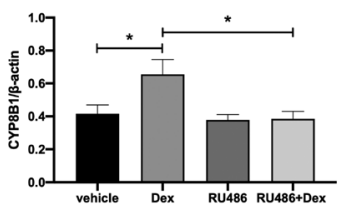

Figure 4

GCs regulate AKR1D1 expression through GR activation. Dexamethasone treatment decreases AKR1D1 mRNA (A) and protein expression (B). Addition of the glucocorticoid receptor antagonist RU486 $(5 \mu \mathrm{M}, 24 \mathrm{~h})$ in the dexamethasone-treated HepG2 cells normalises the expression levels of AKR1D1 ( $A$ and B). RU486 also normalises the dexamethasone-induced expression of CYP8B1 ( $C$ and D). Representative Western blot images are shown, and formal quantification was performed in $n=5$ replicates. Representative Western blot images are shown, and formal quantification was performed in $n=5$ replicates. qPCR data were normalised to 18SrRNA. Data are presented as mean \pm S.E. of $n=5$ experiments, performed in triplicate, $* P<0.05, * \star P<0.01, * \star \star P P<0.001$, compared to vehicle-treated controls. 
Table 1 mRNA expression analysis following $24 \mathrm{~h}$ dexamethasone treatment in Huh7 cells.

\begin{tabular}{|c|c|c|c|}
\hline Gene & Vehicle & Dexamethasone & $P$-value \\
\hline$A K R 1 D 1$ & $0.81 \pm 0.04$ & $0.66 \pm 0.04^{b}$ & $<0.001$ \\
\hline GILZ & $1.15 \pm 0.12$ & $1.25 \pm 0.11^{a}$ & 0.037 \\
\hline DUSP1 & $1.05 \pm 0.15$ & $1.14 \pm 0.17 a$ & 0.024 \\
\hline CYP7A1 & $0.92 \pm 0.04$ & $1.08 \pm 0.02^{a}$ & 0.021 \\
\hline CYP8B1 & $0.44 \pm 0.1$ & $0.70 \pm 0.12^{b}$ & $<0.001$ \\
\hline HSD3B7 & $0.56 \pm 0.05$ & $0.69 \pm 0.06^{a}$ & 0.015 \\
\hline 11BHSD2 & $0.52 \pm 0.10$ & $0.50 \pm 0.11$ & 0.613 \\
\hline
\end{tabular}

Dexamethasone treatment ( $500 \mathrm{nM}, 24 \mathrm{~h}$ ) significantly decreases the expression of AKR1D1 and increases the expression of GILZ, DUSP1, CYP7A1, CYP8B1 and HSD3B7 in Huh7 human hepatoma cells. qPCR data were normalised to 18SrRNA. Data are presented as mean \pm s.E. of $n=5$ experiments, performed in triplicate, $a P<0.05, b P<0.001$, compared to vehicle-treated controls.

HSS1101183, Suppementary Fig. 3A and B). Mirroring the impact of dexamethasone treatment, and in the absence of steroid hormone supplementation in the cell media, $A K R 1 D 1$ knockdown also increased the expression of PEPCK, PC, FBP1 and GYS1 (Fig. 6A). To confirm that the effect of AKR1D1 knockdown on gluconeogenic gene expression is not siRNA specific, additional experiments using a second siRNA variant (HSS1101184) were performed in HepG2 cells. The results revealed similar upregulation of PEPCK, PC and FBP1 expression, following AKR1D1 knockdown (Supplementary Fig. 3C and D). Additional AKR1D1 knockdown experiments were also performed in Huh7 cells, revealing similar changes in gene expression with increased PEPCK, PC and FBP1 mRNA levels, following AKR1D1 knockdown. The data are summarised in Table 2.

AKR1D1 knockdown has been previously shown to result in alterations in both FXR and LXR activation, due to decreases in primary BA synthesis and increases in oxysterol accumulation, respectively (Janowski et al. 1996, Nikolaou et al. 2019b). We proposed that FXR agonism and/or LXR antagonism would have the potential to rescue the phenotype in our cells. Cell treatments using the FXR agonist GW4064 $(5 \mu \mathrm{M}, 24 \mathrm{~h})$ normalised the expression of GYS1 to levels seen in scrambled-transfected cells, but failed to rescue the upregulation of PEPCK, PC or FBP1 expression, caused by AKR1D1 knockdown (Fig. 6B). Additional treatments with the LXR $\alpha$ and LXR $\beta$ antagonists 22(S)-Hydroxycholesterol $(10 \mu \mathrm{M}, 24 \mathrm{~h})$ and GSK2033 (100 nM, $24 \mathrm{~h})$ also failed to restore PEPCK, PC or FBP1 expression, suggesting that the observed phenotype is not driven by increased LXR activation (Supplementary Fig. 4A and B).

Oxysterols and cholesterol metabolites have been recently shown to activate the GR (Voisin et al. 2017, Silvente-Poirot et al. 2018). In AKR1D1 knockdown cells, treatments with RU486 treatment $(5 \mu \mathrm{M}, 24 \mathrm{~h})$ limited the induction of PEPCK and GYS1 levels, suggesting that this observation was mediated, at least in part, through activation of the GR. However, RU486 treatment failed to rescue the up-regulation of $P C$ or FBP1 seen in AKR1D1 knockdown cells (Fig. 6C).

In addition to LXR and GR, oxysterols are endogenous ligands of the Pregnane-X-Receptor (PXR) (Shenoy et al. 2004a,b, Li et al. 2007). Treatment of AKR1D1 knockdown cells with the PXR antagonist SPA70 $(10 \mu \mathrm{M}, 24 \mathrm{~h})$ limited the increase in gene expression of $P C, F B P 1$ and GYS1,
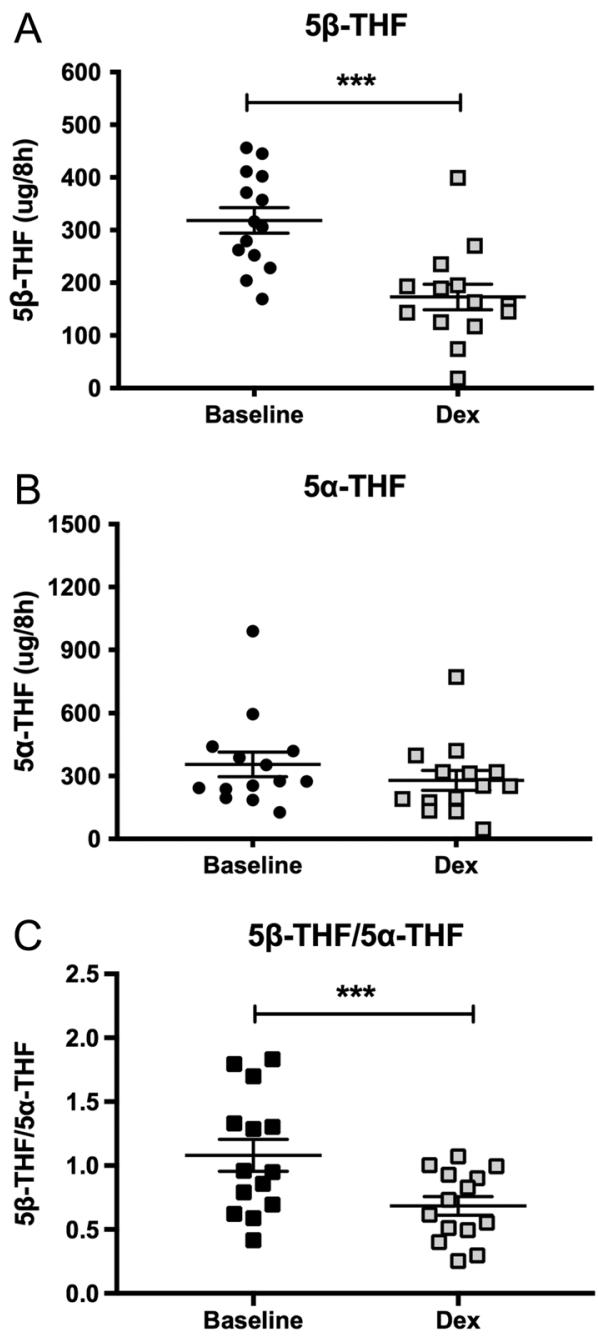

Figure 5

Synthetic GCs down-regulate AKR1D1 activity in vivo. Urine $5 \beta$-tetrahydrocortisol ( $5 \beta$-THF) levels decrease following over-night dexamethasone treatment, compared to overnight samples without treatment (A). There is no alteration in $5 \alpha$-tetrahydrocortisol ( $5 \alpha$-THF) levels (B). The $5 \beta-T H F / 5 \alpha-$ THF ratio decreased following dexamethasone treatment, indicative of decreased AKR1D1 activity (C). Data are presented as mean \pm s.E. of $n=14$ participants, $* \star * P<0.001$. 

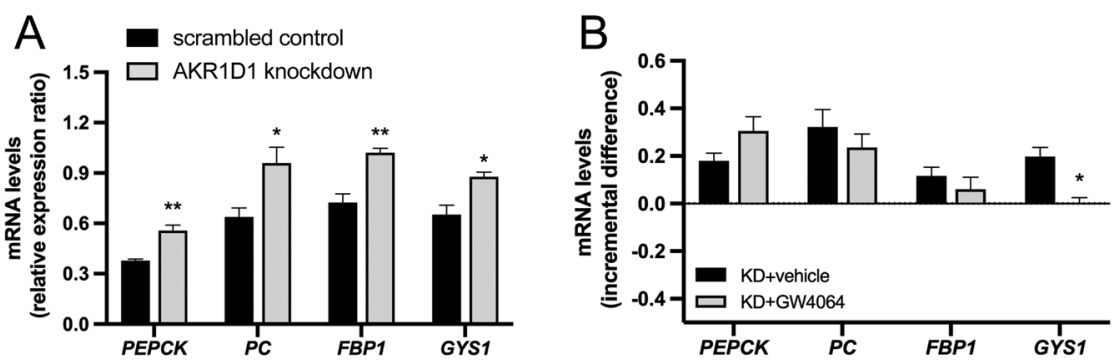

\section{Figure 6}

AKR1D1 silencing drives hepatic gluconeogenic and glycogenic gene expression. AKR1D1 knockdown (grey bars) increases the expression of PEPCK, PC, FBP1 and GYS1 (A). GW4064 treatment (FXR agonist: $5 \mu \mathrm{M}, 24 \mathrm{~h}$ ) normalises the expression of GYS1 in AKR1D1 knockdown cells to levels seen in scrambled controls (B). RU486 treatment (GR antagonist: $5 \mu \mathrm{M}, 24 \mathrm{~h}$ ) limits the increase in the expression of PEPCK and GYS1 in AKR1D1 knockdown cells (C). The PXR antagonist, SPA70 $(10 \mu \mathrm{M}, 24 \mathrm{~h})$, limits the
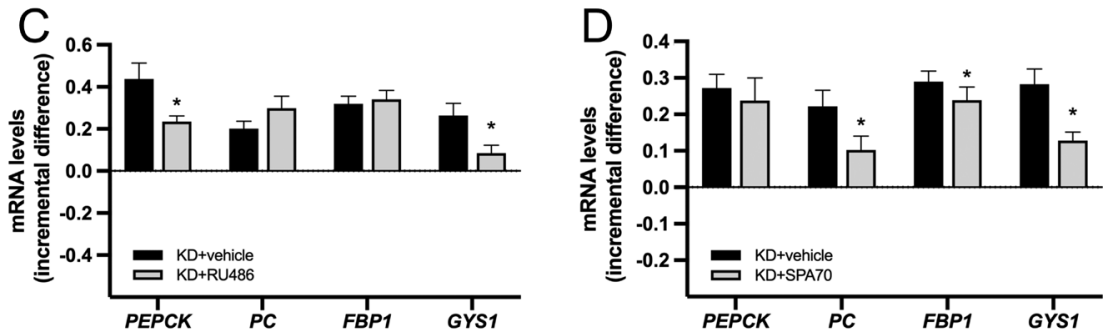
increase in the expression of $P C, F B P 1$ and GYS1 seen in AKR1D1 knockdown cells (D).

Representative Western blot images are shown, and formal quantification was performed in $n=5$ replicates. QPCR data were normalised to 18SrRNA. Data are presented as mean \pm S.E. of $n=5$ experiments, performed in triplicate, $\star P<0.05, * * P<0.01, * * * P<0.001$, compared to vehicle-treated or scrambled-transfected controls. KD, AKR1D1 knockdown.

indicative of an additional PXR activation mechanism of action (Fig. 6D).

\section{Discussion}

We show that although AKR1D1 represents a crucial step in endogenous cortisol clearance, it clears synthetic steroids poorly in comparison. We demonstrate that dexamethasone decreases expression and activity of AKR1D1 in vitro and in vivo (without any effect on $3 \alpha$-HSD activity, as evidenced by the lack of change in $5 \alpha$-THF levels) and, finally, we reveal that the actions of AKR1D1 to regulate the expression of genes involved in glucose metabolism are mediated through FXR, GR and PXR activation.

Synthetic GCs, including dexamethasone, prednisone and prednisolone, are frequently prescribed for a variety of oncological and inflammatory conditions (van Staa et al. 2000, Wooldridge et al. 2001, Amin et al. 2014).

Table 2 mRNA expression analysis of gluconeogenic and glycogen synthesis genes in Huh7 cells, following AKR1D1 knockdown.

\begin{tabular}{|c|c|c|c|}
\hline Gene & Scrambled control & AKR1D1 knockdown & P-value \\
\hline AKR1D1 & $0.87 \pm 0.11$ & $0.09 \pm 0.01 \mathrm{a}$ & 0.006 \\
\hline PEPCK & $0.59 \pm 0.09$ & $0.71 \pm 0.08^{b}$ & $<0.001$ \\
\hline$P C$ & $0.74 \pm 0.05$ & $0.96 \pm 0.05^{a}$ & 0.003 \\
\hline FBP1 & $0.18 \pm 0.006$ & $0.32 \pm 0.01 a$ & 0.005 \\
\hline GYS1 & $0.78 \pm 0.11$ & $0.87 \pm 0.12$ & 0.22 \\
\hline
\end{tabular}

AKR1D1 knockdown significantly increases the expression of $P E P C K, P C$ and $F B P 1$ in Huh7 human hepatoma cells. qPCR data were normalised to 18SrRNA. Data are presented as mean \pm s.E. of $n=4$ experiments, performed in duplicate, a $P<0.01, \mathrm{~b} P<0.001$, compared to scrambledtransfected controls.
Although less efficiently cleared than cortisol, we did observe some prednisolone clearance by AKR1D1, with even more limited metabolism of dexamethasone. Considering the crucial role of AKR1D1 to metabolise endogenous cortisol and cortisone, the impaired clearance of synthetic GCs that we have observed suggests an additional mechanism (over and above potency of GR activation), through which synthetic GCs may have more potent actions (both therapeutically desirable antiinflammatory and anti-proliferative, but also undesirable metabolic and musculoskeletal side effects).

The potential role of steroid hormones, including GCs and androgens, to regulate the expression of the A-ring reductases is poorly described and has been predominantly focused on the role of androgens, only (Berman et al. 1995, Torres \& Ortega 2003, Li et al. 2011). In our study, we have demonstrated that GCs decrease hepatic AKR1D1 expression both in vitro and in vivo and that this effect is mediated by activation of the GR. It is likely that these effects are mediated through glucocorticoid response elements within the promoter of $A K R 1 D 1$; indeed, a study from Nakamoto et al. (Nakamoto et al. 2017) has recently shown putative GR binding sites in the AKR1D1 gene promoter in HepG2 cells.

Published studies have shown that over-expression of AKR1D1 regulates a variety of cytochrome P450 enzymes, including increased expression of CYP3A4 (Chaudhry et al. 2013). Modulation of CYP3A4 activity has a profound influence of the availability of synthetic GCs; CYP3A4 inhibition along with concomitant synthetic GC administration frequently leads to the development of iatrogenic Cushing's syndrome (Mahlab-Guri et al. 2011, Bernecker et al. 2012). Therefore, down-regulation 
of AKR1D1 by GCs might lead to decreased CYP3A4 and further exacerbate the adverse effects of prescribed steroids through both CYP3A4 and AKR1D1 dependent mechanisms.

AKR1D1 is down-regulated in patients with type 2 diabetes and we have recently shown a similar decrease in expression with advancing severity of non-alcoholic fatty liver disease (NAFLD) (Valanejad et al. 2018, Nikolaou et al. $2019 b$ ). In this context, AKR1D1 knockdown increased the expression of key enzymes involved in lipogenesis as well as increasing functional de novo lipogenesis, as measured by deuterated water incorporation into fatty acids (Nikolaou et al. 2019b). The data from our study now provide additional evidence of the adverse impact of AKR1D1 down-regulation, here to drive gluconeogenesis, with the potential to fuel hepatic glucose output. The down-regulation of AKR1D1 by synthetic steroids may therefore be an important contributing factor to the adverse metabolic features associated with their use.

Oxysterols, the oxidised derivatives of cholesterol, are predominantly, although not exclusively, produced in the liver through activity of the cytochrome P450 (CYP) enzyme family (Guillemot-Legris et al. 2016), and they serve as potent ligands for many nuclear receptors including the LXRs, GR, PXR and the retinoic acid receptor-related orphan receptors (RORs) (Ma \& Nelson 2019). In this regard, there is compelling evidence on the role of oxysterols as important mediators of metabolic syndrome (Tremblay-Franco et al. 2015, GuillemotLegris et al. 2016, Mutemberezi et al. 2016). Indeed, some oxysterols are now used as biomarkers for monitoring a variety of pathologies, including atherosclerosis, BA diarrhea and Alzheimer's disease (Eusufzai et al. 1993, Wang et al. 2016, Zmysłowski \& Szterk 2019). In our study, we were not able to directly measure cell media oxysterol levels; however, we have previously shown that AKR1D1 knockdown results in decreased primary BA formation (Nikolaou et al. 2019b) potentially leading to increased accumulation of $7 \alpha$-hydroxycholestenone and $7 \alpha, 12 \alpha$-dihydroxycholestenone levels (oxysterols that are AKR1D1 substrates) in the cell media.

AKR1D1 has a key role in BA synthesis and drives the formation of cholic acid and chenodeoxycholic acid. Endorcing our observations, dexamethasone has been shown to increase the expression of CYP7A1 and CYP8B1 in both human and rat hepatocytes (Princen et al. 1989, Ellis et al. 1998, Mörk et al. 2016). In rodent models, data have been conflicting; in rats and mice, treatment with dexamethasone and prednisolone, respectively, resulted in decreased BA synthesis, as measured by decreased
Cyp7a1 and Cyp8b1 expression and decreased faecal BA excretion. However, there was enhanced enterohepatic cycling of BAs with elevated plasma BA levels and biliary BA secretion (Out et al. 2014, Xiao et al. 2016). In contrast, another study has demonstrated that dexamethasone exposure to neonatal rats increased the expression of genes involved in the synthesis and enterohepatic cycling of BAs, including Cyp7a1, Cyp8b1 and sodium taurocholate co-transporting polypeptide (Ntcp) (Liu et al. 2008).

The role of GCs on hepatic gluconeogenesis and glycogen synthesis has been extensively investigated. GCs increase the transcription of the gluconeogenic genes PEPCK, PC, FBP1 and GYS1 and their action is predominantly conveyed through activation of the GR (Stalmans \& Laloux 1979, Kuo et al. 2015). In our study, AKR1D1 knockdown mimicked the cellular phenotype of GC (dexamethasone) treatment. Although we have previously demonstrated the ability of AKR1D1 knockdown to increase hepatic intracellular glycogen storage (Nikolaou et al. 2019b), this is our first effort to elucidate the mechanistic insight of the observed phenotype. Plausible hypotheses have been that this arises as a result of either impaired FXR activation, due to reduced primary BA synthesis, or increased accumulation of oxysterols, which are able to bind to and activate the GR (Voisin et al. 2017, Silvente-Poirot et al. 2018). In AKR1D1 knockdown cells, FXR agonism normalised GYS1 expression only; however, we were able to partially restore the gene expression profiles through the use of the GR antagonist RU486, suggesting that some of the observed changes are also driven by GR activation. Nevertheless, RU486 treatment did not correct all the changes that were observed.

Recent studies have implicated PXR in the regulation of glucose homeostasis. In vitro, data have been conflicting; in Huh7 cells, PXR activation using the PXR agonist rifampicin has been shown to repress gluconeogenic gene transcription (Kodama et al. 2007) while, in another study using HepG2 cells, rifampicin induced PEPCK expression (Gotoh \& Negishi 2014). The latter findings are in agreement with clinical studies, where rifampicin increases blood glucose levels in humans (Rysä et al. 2013, Hakkola et al. 2016). Consistent with this, our data revealed that the gene expression phenotype associated with AKR1D1 knockdown was partially attributable to PXR activation.

In conclusion, we have shown that AKR1D1 poorly metabolises synthetic GCs and that synthetic GCs decrease AKR1D1 expression and activity in the liver, potentially fueling the adverse metabolic phenotype associated with

This work is licensed under a Creative Commons Attribution 4.0 International License. 
their use. In vitro, AKR1D1 down-regulation mimics the action of GCs in driving hepatic gluconeogenesis and glycogen storage. As such, this represents an additional novel mechanism by which glucocorticoids indirectly regulate glucose metabolism highlighting, in total, the complex role of AKR1D1 to govern the activation of multiple nuclear hormone receptors, with significant implications for the regulation of metabolic phenotype within the liver.

\section{Supplementary materials}

This is linked to the online version of the paper at https://doi.org/10.1530/ JOE-19-0473.

\section{Declaration of interest}

The authors have nothing to declare. T M P is a consultant for Research Institute for Fragrance Materials, is a recipient of a sponsored research agreement from Forendo, and is founding director of Penzymes LLC. M J W and R R are employees and stock holders in Diurnal Ltd. D D is a consultant to Diurnal Ltd.

\section{Funding}

This work was supported by the Medical Research Council (program grant to J W T, ref. MR/P011462/1); NIHR Oxford Biomedical Research Centre (principal investigator award to J W T); British Heart Foundation (senior fellowship to L H, ref. FS/15/56/31645); National Institute of Environmental Health Sciences (P30-ES013508 awarded to T M P); NIHR Birmingham Biomedical Research Centre (BRC-1215-20009 to W A) and the Wellcome Trust (Investigator Award 209492/Z/17/Z to W A).

\section{Author contribution statement}

The study was developed by N N, L L G and J W T. N N, B G K, B A H, K M, $S \mathrm{G}$ and $\mathrm{W}$ A designed the methods. N N, A A, N A and A S performed the investigation. $\mathrm{N} \mathrm{N}$ wrote the manuscript and it was reviewed and edited by N N, D D, M J W, R R, T M P, B G K, L H, W A and J W T. J W T performed supervision and acquired the funding.

\section{Acknowledegments}

The views expressed are those of the author(s) and not necessarily those of the NHS, the NIHR, the Department of Health or the National Institute of Environmental Health.

\section{References}

Amin A, Sam AH \& Meeran K 2014 Glucocorticoid replacement. BMJ 349 g4843. (https://doi.org/10.1136/bmj.g4843)

Berman DM, Tian H \& Russell DW 1995 Expression and regulation of steroid 5 alpha-reductase in the urogenital tract of the fetal rat. Molecular Endocrinology 9 1561-1570. (https://doi.org/10.1210/ mend.9.11.8584033)
Bernecker C, West TB, Mansmann G, Scherbaum WA \& Willenberg HS 2012 Hypercortisolism caused by ritonavir associated inhibition of CYP3A4 under inhalative glucocorticoid therapy: 2 case reports and a review of the literature. Experimental and Clinical Endocrinology and Diabetes 120 125-127. (https://doi. org/10.1055/s-0031-1297993)

Chaudhry AS, Thirumaran RK, Yasuda K, Yang X, Fan Y, Strom SC \& Schuetz EG 2013 Genetic variation in aldo-keto reductase 1D1 (AKR1D1) affects the expression and activity of multiple cytochrome P450s. Drug Metabolism and Disposition: the Biological Fate of Chemicals 41 1538-1547. (https://doi.org/10.1124/dmd.113.051672)

Chen M \& Penning TM 2014 5 $\beta$-Reduced steroids and human $\Delta 4$-3ketosteroid 5 $\beta$-reductase (AKR1D1). Steroids 83 17-26. (https://doi. org/10.1016/j.steroids.2014.01.013)

Chen M, Drury JE \& Penning TM 2011 Substrate specificity and inhibitor analyses of human steroid 5 $\beta$-reductase (AKR1D1). Steroids $\mathbf{7 6}$ 484-490. (https://doi.org/10.1016/j.steroids.2011.01.003)

Dube S, Slama MQ, Basu A, Rizza RA \& Basu R 2015 Glucocorticoid excess increases hepatic 11 $\beta$-HSD1 activity in humans: implications in steroid-induced diabetes. Journal of Clinical Endocrinology and Metabolism 100 4155-4162. (https://doi.org/10.1210/jc.2015-2673)

Ellis E, Goodwin B, Abrahamsson A, Liddle C, Mode A, Rudling M, Bjorkhem I \& Einarsson C 1998 Bile acid synthesis in primary cultures of rat and human hepatocytes. Hepatology 27 615-620. (https://doi. org/10.1002/hep.510270241)

Eusufzai S, Axelson M, Angelin B \& Einarsson K 1993 Serum 7 $\alpha$-hydroxy4-cholesten-3-one concentrations in the evaluation of bile acid malabsorption in patients with diarrhoea: correlation to SeHCAT test. Gut 34 698-701. (https://doi.org/10.1136/gut.34.5.698)

Faucher F, Cantin L, Luu-The V, Labrie F \& Breton R 2008 The crystal structure of human $\Delta 4$-3-ketosteroid $5 \beta$-reductase defines the functional role of the residues of the catalytic tetrad in the steroid double bond reduction mechanism. Biochemistry 47 8261-8270. (https://doi.org/10.1021/bi800572s)

Gotoh S \& Negishi M 2014 Serum- and glucocorticoid-regulated kinase 2 determines drug-activated pregnane $\mathrm{X}$ receptor to induce gluconeogenesis in human liver cells. Journal of Pharmacology and Experimental Therapeutics 348 131-140. (https://doi.org/10.1124/ jpet.113.209379)

Guillemot-Legris O, Mutemberezi V \& Muccioli GG 2016 Oxysterols in metabolic syndrome: From bystander molecules to bioactive lipids. Trends in Molecular Medicine 22 594-614. (https://doi.org/10.1016/j. molmed.2016.05.006)

Hakkola J, Rysä J \& Hukkanen J 2016 Regulation of hepatic energy metabolism by the nuclear receptor PXR. Biochimica et Biophysica Acta 1859 1072-1082. (https://doi.org/10.1016/j.bbagrm.2016.03.012)

Hawley JM, Owen LJ, Debono M, Newell-Price J \& Keevil BG 2018 Development of a rapid liquid chromatography tandem mass spectrometry method for the quantitation of serum dexamethasone and its clinical verification. Annals of Clinical Biochemistry $\mathbf{5 5}$ 665-672. (https://doi.org/10.1177/0004563218766566)

Jamieson PM, Chapman KE, Edwards CRW \& Seckl JR 1995 $11 \beta$-Hydroxysteroid dehydrogenase is an exclusive $11 \beta$-reductase in primary cultures of rat hepatocytes: effect of physicochemical and hormonal manipulations. Endocrinology 136 4754-4761. (https://doi. org/10.1210/endo.136.11.7588203)

Janowski BA, Willy PJ, Devi TR, Falck JR \& Mangelsdorf DJ 1996 An oxysterol signalling pathway mediated by the nuclear receptor LXR alpha. Nature 383 728-731. (https://doi.org/10.1038/383728a0)

Kodama S, Moore R, Yamamoto Y \& Negishi M 2007 Human nuclear pregnane $\mathrm{X}$ receptor cross-talk with CREB to repress cAMP activation of the glucose-6-phosphatase gene. Biochemical Journal 407 373-381. (https://doi.org/10.1042/BJ20070481)

Kondo KH, Kai MH, Setoguchi Y, Eggertsen G, Sjöblom P, Setoguchi T, Okuda KI \& Björkhem I 1994 Cloning and expression of cDNA of human delta 4-3-oxosteroid 5 beta-reductase and substrate specificity

This work is licensed under a Creative Commons Attribution 4.0 International License. 
of the expressed enzyme. European Journal of Biochemistry 219 357-363. (https://doi.org/10.1111/j.1432-1033.1994.tb19947.x)

Kuo T, McQueen A, Chen TC \& Wang JC 2015 Regulation of glucose homeostasis by glucocorticoids. Advances in Experimental Medicine and Biology 872 99-126. (https://doi.org/10.1007/978-1-4939-2895-8_5)

Li T, Chen W \& Chiang JYL 2007 PXR induces CYP27A1 and regulates cholesterol metabolism in the intestine. Journal of Lipid Research 48 373-384. (https://doi.org/10.1194/jlr.M600282-JLR200)

Li J, Ding Z, Wang Z, Lu JF, Maity SN, Navone NM, Logothetis CJ, Mills GB \& Kim J 2011 Androgen regulation of $5 \alpha$-reductase isoenzymes in prostate cancer: implications for prostate cancer prevention. PLOS ONE 6 e28840. (https://doi.org/10.1371/journal. pone.0028840)

Liu Y, Havinga R, Van Der Leij FR, Boverhof R, Sauer PJJ, Kuipers F \& Stellaard F 2008 Dexamethasone exposure of neonatal rats modulates biliary lipid secretion and hepatic expression of genes controlling bile acid metabolism in adulthood without interfering with primary bile acid kinetics. Pediatric Research 63 375-381. (https://doi.org/10.1203/ PDR.0b013e318165b8af)

Ma L \& Nelson ER 2019 Oxysterols and nuclear receptors. Molecular and Cellular Endocrinology 484 42-51. (https://doi.org/10.1016/j. mce.2019.01.016)

Mahlab-Guri K, Asher I, Gradstein S, Zung A, Radian-Sade S, Elbirt D \& Sthoeger Z 2011 Inhaled fluticasone causes iatrogenic Cushing's syndrome in patients treated with ritonavir. Journal of Asthma $\mathbf{4 8}$ 860-863. (https://doi.org/10.3109/02770903.2011.606580)

Morgan SA, McCabe EL, Gathercole LL, Hassan-Smith ZK, Larner DP, Bujalska IJ, Stewart PM, Tomlinson JW \& Lavery GG 2014 11 $\beta$-HSD1 is the major regulator of the tissue-specific effects of circulating glucocorticoid excess. PNAS 111 E2482-E2491. (https://doi. org/10.1073/pnas.1323681111)

Mörk LM, Strom SC, Mode A \& Ellis ECS 2016 Addition of dexamethasone alters the bile acid composition by inducing CYP8B1 in primary cultures of human hepatocytes. Journal of Clinical and Experimental Hepatology 6 87-93. (https://doi.org/10.1016/j.jceh.2016.01.007)

Mutemberezi V, Guillemot-Legris O \& Muccioli GG 2016 Oxysterols: from cholesterol metabolites to key mediators. Progress in Lipid Research 64 152-169. (https://doi.org/10.1016/j.plipres.2016.09.002)

Nakamoto M, Ishihara K, Watanabe T, Hirosue A, Hino S, Shinohara M, Nakayama H \& Nakao M 2017 The glucocorticoid receptor regulates the ANGPTL4 gene in a CTCF-mediated chromatin context in human hepatic cells. PLOS ONE 12 e0169225. (https://doi.org/10.1371/ journal.pone.0169225

Nasiri M, Nikolaou N, Parajes S, Krone NP, Valsamakis G, Mastorakos G, Hughes B, Taylor A, Bujalska IJ, Gathercole LL, et al. 2015 $5 \alpha$-Reductase type 2 regulates glucocorticoid action and metabolic phenotype in human hepatocytes. Endocrinology 156 2863-2871. (https://doi.org/10.1210/en.2015-1149)

Nikolaou N, Gathercole LL, Kirkwood L, Dunford JE, Hughes BA, Gilligan LC, Oppermann U, Penning TM, Arlt W, Hodson L, et al. 2019a AKR1D1 regulates glucocorticoid availability and glucocorticoid receptor activation in human hepatoma cells. Journal of Steroid Biochemistry and Molecular Biology 189 218-227. (https://doi. org/10.1016/j.jsbmb.2019.02.002)

Nikolaou N, Gathercole LL, Marchand L, Althari S, Dempster NJ, Green CJ, van de Bunt M, McNeil C, Arvaniti A, Hughes BA, et al. $2019 b$ AKR1D1 is a novel regulator of metabolic phenotype in human hepatocytes and is dysregulated in non-alcoholic fatty liver disease. Metabolism: Clinical and Experimental 99 67-80. (https://doi org/10.1016/j.metabol.2019.153947)

Onishi Y, Noshiro M, Shimosato T \& Okuda K 1991 Molecular cloning and sequence analysis of cDNA encoding $\Delta 4$-3-ketosteroid $5 \beta$-reductase of rat liver. FEBS Letters 283 215-218. (https://doi. org/10.1016/0014-5793(91)80591-P)
Out C, Dikkers A, Laskewitz A, Boverhof R, Van Der Ley C, Kema IP, Wolters H, Havinga R, Verkade HJ, Kuipers F, et al. 2014 Prednisolone increases enterohepatic cycling of bile acids by induction of Asbt and promotes reverse cholesterol transport. Journal of Hepatology $\mathbf{6 1}$ 351-357. (https://doi.org/10.1016/j.jhep.2014.03.025)

Owen LJ, Gillingwater S \& Keevil BG 2005 Prednisolone measurement in human serum using liquid chromatography tandem mass spectrometry. Annals of Clinical Biochemistry 42 105-111. (https://doi. org/10.1258/0004563053492810)

Palermo M, Shackleton CHL, Manterof F \& Stewart PM 1996 Urinary free cortisone and the assessment of $11 \beta$-hydroxysteroid dehydrogenase activity in man. Clinical Endocrinology 45 605-611. (https://doi org/10.1046/j.1365-2265.1996.00853.x)

Pfaffl MW 2001 A new mathematical model for relative quantification in real-time RT-PCR. Nucleic Acids Research 29 e45. (https://doi. org/10.1093/nar/29.9.e45)

Princen HMG, Meijer P \& Hofstee B 1989 Dexamethasone regulates bile acid synthesis in monolayer cultures of rat hepatocytes by induction of cholesterol 7a-hydroxylase. Biochemical Journal 262 341-348. (https://doi.org/10.1042/bj2620341)

Rysä J, Buler M, Savolainen MJ, Ruskoaho H, Hakkola J \& Hukkanen J 2013 Pregnane X receptor agonists impair postprandial glucose tolerance. Clinical Pharmacology and Therapeutics 93 556-563. (https:// doi.org/10.1038/clpt.2013.48)

Schneiter P \& Tappy L 1997 Kinetics of dexamethasone-induced alterations of glucose metabolism in healthy humans. American Journal of Physiology: Endocrinology and Metabolism 275 806-213. (https://doi.org/10.1152/ajpendo.1998.275.5.E806)

Shackleton CHL 1986 Profiling steroid hormones and urinary steroids. Journal of Chromatography 379 91-156. (https://doi.org/10.1016/ S0378-4347(00)80683-0)

Shenoy SD, Spencer TA, Mercer-Haines NA, Abdolalipour M, Wurster WL, Runge-Morris M \& Kocarek TA 2004a Induction of CYP3A by 2,3-oxidosqualene:lanosterol cyclase inhibitors is mediated by an endogenous squalene metabolite in primary cultured rat hepatocytes. Molecular Pharmacology 65 1302-1312. (https://doi.org/10.1124/ mol.65.5.1302)

Shenoy SD, Spencer TA, Mercer-Haines NA, Alipour M, Gargano MD, Runge-Morris M \& Kocarek TA 2004b CYP3A induction by liver X receptor ligands in primary cultured rat and mouse hepatocytes is mediated by the pregnane X receptor. Drug Metabolism and Disposition 32 66-71. (https://doi.org/10.1124/dmd.32.1.66)

Silvente-Poirot S, Dalenc F \& Poirot M 2018 The effects of cholesterolderived oncometabolites on nuclear receptor function in cancer. Cancer Research 78 4803-4808. (https://doi.org/10.1158/0008-5472. CAN-18-1487)

Sistare FD \& Haynes RC 1985 Acute stimulation by glucocorticoids of gluconeogenesis from lactate/pyruvate in isolated hepatocytes from normal and adrenalectomized rats. Journal of Biological Chemistry 260 12754-12760.

Stalmans W \& Laloux M 1979 Glucocorticoids and hepatic glycogen metabolism. Monographs on Endocrinology 12 517-533. (https://doi. org/10.1007/978-3-642-81265-1_27)

Torres JM \& Ortega E 2003 Differential regulation of steroid 5alphareductase isozymes expression by androgens in the adult rat brain. FASEB Journal 17 1428-1433. (https://doi.org/10.1096/fj.02 1119 com)

Tounian P, Schneiter P, Henry S, Delarue J \& Tappy L 1997 Effects of dexamethasone on hepatic glucose production and fructose metabolism in healthy humans. American Journal of Physiology $\mathbf{2 7 3}$ E315-E320. (https://doi.org/10.1152/ajpendo.1997.273.2.E315)

Tremblay-Franco M, Zerbinati C, Pacelli A, Palmaccio G, Lubrano C, Ducheix S, Guillou H \& Iuliano L 2015 Effect of obesity and metabolic syndrome on plasma oxysterols and fatty acids https://joe.bioscientifica.com https://doi.org/10.1530/JOE-19-0473 (c) 2020 The authors Published by Bioscientifica Ltd. Printed in Great Britain

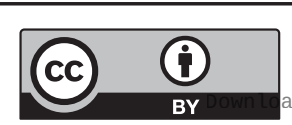

This work is licensed under a Creative Commons Attribution 4.0 International License. Ated from Bioscientifica com at 04/26/2023 02:10:43PM 
in human. Steroids 99 287-292. (https://doi.org/10.1016/j. steroids.2015.03.019)

Valanejad L, Nadolny C, Shiffka S, Chen Y, You S \& Deng R 2017 Differential feedback regulation of $\Delta 4$-3-oxosteroid $5 \beta$-reductase expression by bile acids. PLOS ONE 12 e0170960. (https://doi. org/10.1371/journal.pone.0170960)

Valanejad L, Ghareeb M, Shiffka S, Nadolny C, Chen Y, Guo L, Verma R, You S, Akhlaghi F \& Deng R 2018 Dysregulation of $\Delta 4$-3-oxosteroid $5 \beta$-reductase in diabetic patients: implications and mechanisms. Molecular and Cellular Endocrinology 470 127-141. (https://doi. org/10.1016/j.mce.2017.10.005)

van Staa TP, Leufkens HGM, Abenhaim L, Begaud B, Zhang B \& Cooper C 2000 Use of oral corticosteroids in the United Kingdom. QJM 93 105-111. (https://doi.org/10.1093/qjmed/93.2.105)

Voisin M, de Medina P, Mallinger A, Dalenc F, Huc-Claustre E, Leignadier J, Serhan N, Soules R, Ségala G, Mougel A, et al. 2017 Identification of a tumor-promoter cholesterol metabolite in human breast cancers acting through the glucocorticoid receptor. PNAS 114 E9346-E9355. (https://doi.org/10.1073/pnas.1707965114)

Wang HL, Wang YY, Liu XG, Kuo SH, Liu N, Song QY \& Wang MW 2016 Cholesterol, 24-hydroxycholesterol, and 27-hydroxycholesterol as surrogate biomarkers in cerebrospinal fluid in mild cognitive impairment and Alzheimer's disease: a meta-analysis. Journal of Alzheimer's Disease 51 45-55. (https://doi.org/10.3233/JAD-150734)

Wooldridge JE, Anderson CM \& Perry MC 2001 Corticosteroids in advanced cancer. Oncology 15 225-234; discussion 234. (https://doi. org/10.1136/bmj.305.6860.969)

Xiao Y, Yan W, Zhou K, Cao Y \& Cai W 2016 Glucocorticoid treatment alters systemic bile acid homeostasis by regulating the biosynthesis and transport of bile salts. Digestive and Liver Disease 48 771-779. (https://doi.org/10.1016/j.dld.2016.03.022)

Zmysłowski A \& Szterk A 2019 Oxysterols as a biomarker in diseases. Clinica Chimica Acta: International Journal of Clinical Chemistry 491 103-113. (https://doi.org/10.1016/j.cca.2019.01.022)

Received in final form 20 December 2019

Accepted 27 February 2020

Accepted Manuscript published online 27 February 2020 https://joe.bioscientifica.com https://doi.org/10.1530/JOE-19-0473 (c) 2020 The authors Published by Bioscientifica Ltd. Printed in Great Britain
This work is licensed under a Creative Commons Attribution 4.0 International License.

ded from Bioscientifica.com at 04/26/2023 02:10:43PM 